\title{
The Relationship Between the Amount of Breastfeeding and Late-onset Sepsis in Very Low Birth Weight Infants Within 4 Weeks After Birth
}

\section{Xiaoyun Xiong ( $\nabla$ x.xyun@163.com)}

Affifiliated Shenzhen Maternity and Child Healthcare Hospital, Southern Medical University

Huiyan Wang

Shanxi University of Traditional Chinese Medicine

\section{Xueyu Chen}

Affifiliated Shenzhen Maternity and Child Healthcare Hospital, Southern Medical University

\section{Chuanzhong Yang}

Affifiliated Shenzhen Maternity and Child Healthcare Hospital, Southern Medical University

\section{Lilian Chen}

Affifiliated Shenzhen Maternity and Child Healthcare Hospital, Southern Medical University

\section{Bingchun Lin}

Affifiliated Shenzhen Maternity and Child Healthcare Hospital, Southern Medical University

Chun Chen

Affifiliated Shenzhen Maternity and Child Healthcare Hospital, Southern Medical University

\section{Research Article}

Keywords: Very-low-birth-weight infants, premature infants, late-onset sepsis, breastfeeding

Posted Date: February 7th, 2022

DOI: https://doi.org/10.21203/rs.3.rs-1278663/v1

License: (9) This work is licensed under a Creative Commons Attribution 4.0 International License. Read Full License 


\section{Abstract}

Objective: To assess the relationship between the amount of breastfeeding and late-onset sepsis in very low birth weight infants within 4 weeks after birth.

Study Design: In this retrospective study, we analyzed the effect of the breastfeeding ratio of 305 verylow-birth-weight infants on late onset sepsis.

Results: The incidence of late-onset sepsis in the high-breastfeeding group, low-breastfeeding group, and the formula-fed group was $0.49 \%(1 / 203), 7.41 \%(6 / 81)$, and $4.76 \%(1 / 21)$, respectively $(P<0.05)$. Singlefactor logistic regression analysis showed that, in the low-breastfeeding group, the risk of late-onset sepsis higher than that in the high-breastfeeding group, with an OR value of 16.16 (95\% Cl: 1.91, 136.47) $(P<0.05)$. Multivariate logistic regression analysis also confirmed that, compared with the highbreastfeeding group, the low-breastfeeding group had an increased risk of late-onset sepsis, with an OR value of $18.86(95 \% \mathrm{Cl}: 1.91,136.47)(P<0.05)$.

Conclusion: The breastfeeding amount of very-low-birth-weight newborns accounting for more than $60 \%$ of the total feeding amount within four weeks after birth may reduce the risk of late-onset sepsis.

\section{Key Points}

1. Except for LOS, there is no relationship between breastfeeding volume and complications of preterm infants (IVH, ROP, BPD).

2. It is verified that the protective effect of breast milk has a dose effect.

3. VLBWI breast milk intake more than $60 \%$ of total feeding can reduce the incidence of LOS.

4. VLBWI intake a small amount of breast milk mixed feeding or formula feeding may increase the incidence of LOS.

\section{Introduction}

Neonatal sepsis is a clinical syndrome of neonatal infection ${ }^{1}$. According to the time of its occurrence, sepsis can be divided into early-onset sepsis (EOS) and late-onset sepsis (LOS). EOS is related mostly to intrauterine infection, whereas LOS generally occurs 72 hours after birth, and most of the cases are related to the operation, environment, and a low autoimmune function of the child during or after childbirth. The incidence of sepsis in premature infants is $20-38 \%$, and the mortality Breast milk is the preferred feeding rate is $13-19 \%^{2}$, which is one of the common causes of death in premature infants ${ }^{3}$. Premature infants have immature development of various organs and low immunity, which is easy to cause various complications. The earlier the newborn is born, the greater the risk of LOS ${ }^{4}$. About $60 \%$ of neonatal LOS cases come from VLBWI ${ }^{5}$. Compared with Gram-positive bacteria, Gram-negative bacteria 
such as Klebsiella and Escherichia coli are more likely to develop LOS from VLBWI ${ }^{6}$.LOS exerts many adverse effects to newborns, such as necrotizing enterocolitis (NEC), bronchopulmonary dysplasia (BPD), and neurodevelopment ${ }^{5}$, and can affect the growth and development of the newborns and their neurodevelopment ${ }^{6}$.

Breast milk is the preferred feeding for premature infants, which can meet their growth and development needs. It also has a certain immunological protection effect on premature infants. Compared with breast milk of full-term mothers, the colostrum of mothers of premature babies contains higher protein, fat, free amino acids and sodium contents ${ }^{7}$, which can promote the development of newborns and prevent the occurrence of diseases. The essential amino acids provided by breast milk can reduce the risk of neonatal diseases ${ }^{8}$. The study have shown that breastfeeding in premature infants can decrease the occurrence of late-onset sepsis, but the protective effect of breast milk is dose-dependent ${ }^{9}$. Highbreastfeeding for 28 days after birth can reduce the risk of VLBWI LOS and other diseases ${ }^{10}$. Our study analyzed the relationship of breastfeeding intake and the incidence LOS within four weeks after birth for VLBWI.

\section{Materials And Methods}

From July 2018 to June 2019, 305 cases of VLBWI who were born in the Obstetrics Department of Shenzhen Maternity and Child Health Hospital affiliated to Southern Medical University (Shenzhen, Guangdong, China) and were admitted to the Neonatal Intensive Care Unit within 24 hours were the subjects of the study.

The following inclusion criteria were applied: (1) Birth weight < $1500 \mathrm{~g}$; (2) Birth age $\leq 24 \mathrm{~h}$; (3) Feeding started within $24 \mathrm{~h}$ after birth. The exclusion criteria were as follows: (1) Congenital hereditary metabolic diseases or developmental malformations; (2) Discharged or died due to unhealed symptoms within two weeks of hospitalization; (3) Patients who have been clearly diagnosed with bloodstream infection at the time of admission. Parental informed consent was obtained before study enrollment for each infant. This study was approved by the Ethics Committee of Shenzhen Maternity and Child Health Hospital, and all methods have been performed in accordance with the Declaration of Helsinki [SFYLS 2019 NO 119].

After the child was admitted to the Neonatal Intensive Care Unit, the medical staff instructed the family members about the benefits of breastfeeding as soon as possible. The specific content included the following main points: (a): On the day of admission, the doctor explained to the family of the child the beneficial effects of breastfeeding on the growth and development of VLBWI, and encouraged the family to prefer breastfeeding. Admission nurses taught family members the correct methods and precautions for breast milk collection, storage and transportation; (b) Breast milk management had dedicated staff. The breast milk nurses called the family members of the child on the day after the child was admitted to the hospital to once again educate the family on the importance of breastfeeding and the methods of collecting, storing, and transporting breast milk; (c) Open classes for parents were held every Monday and Thursday to ensure that the family members of the children admitted to the Neonatal Intensive Care Unit 
can receive breastfeeding education again and obtain accurate, relevant knowledge of breastfeeding. The basic data of VLBWI were collected in this study, including gestational age, age, gender, mode of delivery, an in vitro fertilization (IVF) or not, Apgar score, intrauterine distress, double entry, and consistency check.

According to the ratio of the breast milk intake to the total intake four weeks after VLBWI birth, they were divided into a high-breastfeeding group (breast milk intake $>60 \%, 203$ cases), a low-breastfeeding group (breast milk intake accounting for a ratio $\leq 60 \%, 81$ cases), and a formula-fed group (no breast milk intake, 21 cases).

The observation indicators of this study included the time of feeding, breast milk intake, total intake, the ratio of breast milk intake to the total intake; and the incidence of LOS. The diagnostic criteria of the complications were in compliance with the guidelines of "Practical Neonatology";. The following diagnostic criteria for LOS were used: isolate pathogenic bacteria from sterile cavity fluids such as blood culture, cerebrospinal fluid, and urine culture. The basis for the diagnosis of LOS was on the premise of abnormal clinical manifestations, meeting any of the following conditions: (1) Non-specific blood test $\geq$ 2 items were positive; (2) Cerebrospinal fluid examination was abnormal; (3) DNA or antigen of special bacteria was detected in the blood.

Statistical analysis SPSS 24.0 software (IBM, Armonk, NY, USA) was used to perform statistical analysis, and normally distributed data were expressed as mean \pm standard deviation $\left(\chi^{2} \pm s\right)$. One-way analysis of variance (ANOVA) was used for making comparison among multiple groups, and count data were presented as frequency and percentage. The $\chi^{2}$ test was employed for making comparison between two groups. The binary logistic regression analysis was used to analyze the relationship between breast milk volume and incidence of LOS; the single factor logistic regression analysis was employed to analyze the relationship between related variables and incidence of LOS; and the multivariate logistic regression analysis was utilized to analyze the relationship between breastfeeding volume and the incidence of LOS. $\mathrm{P}<0.05$ was considered statistically significant.

\section{Results}

\section{General situation}

The study finally included 305 newborns who met the inclusion criteria. There were no statistically significant differences in the basic characteristics of the three groups of VLBWI, such as gestational age, age, gender, and delivery method $(P>0.05)$, (Table 1$)$. 
Table 1

Comparison of general conditions of three groups of VLBWI

\begin{tabular}{|c|c|c|c|c|c|}
\hline & $\begin{array}{l}\text { High } \\
\text { breastfeeding } \\
\text { group }\end{array}$ & $\begin{array}{l}\text { Low } \\
\text { breastfeeding } \\
\text { group }\end{array}$ & $\begin{array}{l}\text { Formula feeding } \\
\text { group }\end{array}$ & $F / \chi^{2}$ & $\begin{array}{l}\mathrm{P} \text { - } \\
\text { value }\end{array}$ \\
\hline $\begin{array}{l}\text { Number of cases } \\
(\mathrm{n})\end{array}$ & 203 & 81 & 21 & & \\
\hline $\begin{array}{l}\text { Gestational week } \\
(w)^{a}\end{array}$ & $29.13 \pm 2.93$ & $29.54 \pm 2.56$ & $29.47 \pm 2.22$ & 0.7 & 0.5 \\
\hline Male (n)b & $113(55.67 \%)$ & $48(59.26 \%)$ & $13(61.90 \%)$ & 0.52 & 0.77 \\
\hline $\begin{array}{l}\text { Normal delivery } \\
(n)^{b}\end{array}$ & 77 (37.93\%) & $29(35.80 \%)$ & 7 (33.33\%) & 0.25 & 0.88 \\
\hline $\begin{array}{l}\text { Amniotic } \\
\text { fluid(clear } n)^{b}\end{array}$ & 192 (94.58\%) & 79 (97.53\%) & 20 (95.24\%) & 1.15 & 0.56 \\
\hline $\operatorname{IVF}(n)^{b}$ & $33(16.26 \%)$ & $11(13.58 \%)$ & $5(23.81 \%)$ & 1.31 & 0.52 \\
\hline $\begin{array}{l}\text { Intrauterine } \\
\text { distress }(n)^{b}\end{array}$ & $16(7.88 \%)$ & $7(8.64 \%)$ & $2(9.52 \%)$ & 0.1 & 0.95 \\
\hline \multirow{2}{*}{$\begin{array}{l}\text { Admission weight } \\
(\mathrm{g})^{\mathrm{c}}\end{array}$} & 1181 & 1300 & 1200 & \multirow[t]{2}{*}{2.83} & \multirow[t]{2}{*}{0.06} \\
\hline & $(995.00-1350.00)$ & $\begin{array}{l}(1083.00- \\
1420.00)\end{array}$ & $\begin{array}{l}(1020.00- \\
1300.00)\end{array}$ & & \\
\hline $\begin{array}{l}1 \text { minute score } \\
\text { (points) }^{c}\end{array}$ & $9.00(7.00-10.00)$ & $9.00(8.00-10.00)$ & $\begin{array}{l}9.00(8.00- \\
10.00)\end{array}$ & 1.17 & 0.31 \\
\hline $\begin{array}{l}\text { Admission age } \\
(\min )^{c}\end{array}$ & $\begin{array}{l}15.00(12.00- \\
20.00)\end{array}$ & $\begin{array}{l}15.00(12.00- \\
19.00)\end{array}$ & $\begin{array}{l}18.00(12.00- \\
21.00)\end{array}$ & 0.44 & 0.65 \\
\hline $\begin{array}{l}\text { Prenatal hormone } \\
\text { foot }(n)^{b}\end{array}$ & $107(52.71 \%)$ & $48(60.00 \%)$ & $12(57.14 \%)$ & 1.28 & 0.53 \\
\hline $\begin{array}{l}\text { Late onset sepsis } \\
\text { (n) }\end{array}$ & $1(0.49 \%)$ & $6(7.41 \%)$ & $1(4.76 \%)$ & 11.24 & 0.003 \\
\hline $\begin{array}{l}\text { Note: }{ }^{\mathrm{a}} \text { is expressec } \\
(\%) \text { and the statisti } \\
\text { value is } \mathrm{K}-\mathrm{W} \text {. }\end{array}$ & $\begin{array}{l}\overline{\mathrm{X}} \pm \mathrm{s} \text {, and the statis } \\
\text { value is } \chi^{2} ; \text { is exp }\end{array}$ & $\begin{array}{l}\text { I value of } t \text { is the } F \\
\text { ed as median(inte }\end{array}$ & $\begin{array}{l}\text { lue; }{ }^{b} \text { is expressec } \\
\text { lartile range), and }\end{array}$ & $\begin{array}{l}\text { Is an ex } \\
\text { e statis }\end{array}$ & $\begin{array}{l}\text { mple } \\
\text { cal }\end{array}$ \\
\hline
\end{tabular}

Feeding status and complications 
Statistically significant differences $(P<0.01)$ were found in the comparison of the incidence of LOS in the high-breastfeeding group, low-breastfeeding group, and the formula-fed group. However, no statistically significant difference was observed in the incidence of BPD, ROP, and IVH $(P>0.05)$, (Table 2).

Table 2

Comparison of different outcomes of three groups of VLBWI

\begin{tabular}{|llllll|}
\hline & $\begin{array}{l}\text { High breastfeeding } \\
\text { group }\end{array}$ & $\begin{array}{l}\text { Low breastfeeding } \\
\text { group }\end{array}$ & $\begin{array}{l}\text { Formula feeding } \\
\text { group }\end{array}$ & $\chi^{2}$ & $\begin{array}{l}\text { P- } \\
\text { value }\end{array}$ \\
\hline IVH & $27(13.93)$ & $8(9.88)$ & $4(19.05)$ & 10.26 & 0.25 \\
\hline LOS & $1(0.49 \%)$ & $6(7.41 \%)$ & $1(4.76 \%)$ & 11.24 & 0.003 \\
\hline ROP & $33(16.26 \%)$ & $7(8.64 \%)$ & $2(9.52 \%)$ & 5.65 & 0.23 \\
\hline BPD & $71(35.15)$ & $29(35.8)$ & $11(52.38)$ & 10.67 & 0.1 \\
\hline $\begin{array}{l}\text { Note: IVH stands for intracranial hemorrhage; LOS stands for late-onset sepsis; ROP stands for } \\
\text { retinopathy of prematurity; BPD stands for bronchopulmonary dysplasia of prematurity; } d \text { compared } \\
\text { with the high breastfeeding group, P<0.05. }\end{array}$ \\
\hline
\end{tabular}

\section{Comparison of the risk of late-onset sepsis among the three groups}

Single-factor logistic analysis of the breastfeeding amount and LOS shows that taking the highbreastfeeding group as the reference group, the low-breastfeeding group had a significantly higher risk of LOS, with OR values of $16.16(95 \% \mathrm{Cl}: 1.91-136.47)$, and the difference was statistically significant $(P<$ 0.05), (Table 3). 
Table 3

Single factor Logistic analysis of LOS in VLBWI

\begin{tabular}{|llll|}
\hline \multicolumn{4}{|l}{ Table3 Single factor Logistic analysis of LOS in VLBWI } \\
\hline & OR-value & $95 \% \mathrm{Cl}$ & P-value \\
\hline Gender & 0.8 & $(0.19,3.40)$ & 0.759 \\
Age & 1.01 & $(0.94,1.09)$ & 0.74 \\
\hline Gestational week & 0.87 & $(0.69,1.08)$ & 0.209 \\
\hline Admission weight & 1 & $(0.99,1.00)$ & 0.021 \\
\hline Proportion of breastfeeding & & & \\
\hline High breastfeeding group & 1 & & \\
\hline Low breastfeeding group & 16.16 & $(1.91,136.47)$ & 0.011 \\
\hline Formula feeding group & 10.1 & $(0.61,167.71)$ & 0.107 \\
\hline
\end{tabular}

\section{Multivariate Logistic analysis of breastfeeding amount and LOS}

Taking the high-breastfeeding group as the reference group, the low-breastfeeding group had an OR value of 18.86 (1.91-136.47), and the difference was statistically significant $(P<0.05)$, the formula-fed group had a LOS OR value of 10.1 (0.61-167.71); After adjustment for related factors, the OR value of LOS in the low-breastfeeding group was 28.92 (2.96-282.24), and the difference was statistically significant $(P<$ 0.05). The OR value of LOS in the formula-fed group was 12.54 (0.69-228.59). (Table 4)

Table 4

Multivariate Logistic analysis of breastfeeding amount and LOS

\begin{tabular}{|lcccc|}
\hline Variable & Model 1 & & Model 2 & \\
\hline & OR $(95 \% \mathrm{Cl})$ & P-value & OR $(95 \% \mathrm{Cl})$ & P-value \\
\hline Group & & & & \\
\hline High breastfeeding group & & $<0.010$ & & $<.010$ \\
\hline Low breastfeeding group & $18.86(1.91,136.47)$ & 0.0106 & $28.92(2.96,282.24)$ & 0.004 \\
\hline Formula feeding group & $10.1(0.61,167.71)$ & 0.1067 & $12.54(0.69,228.59)$ & 0.088 \\
\hline $\begin{array}{l}\text { Note: Model 1 did not adjust the relevant variables; Model 2 adjusted the relevant variables: gender; } \\
\text { age; gestational week; admission weight. }\end{array}$ & & & \\
\hline
\end{tabular}




\section{Discussion}

Due to individual differences and other reasons, mothers of preterm infants cannot produce milk in time after delivery. Such preterm infants are usually fed with donated breast milk or formula milk. In our study, breast milk from their own mothers, and those without breast milk were fed with formula milk (provided uniformly by the hospital).

Boyd et al. ${ }^{11}$ found that the use of donated breast milk for feeding of preterm infants reduced their infection rates. However, the growth and development of preterm infants fed by donated breast milk were slower. Furthermore, preterm infants fed with formula milk had significantly longer oxygen use and mechanical ventilation times ${ }^{12}$; importantly, their growth and neurodevelopment were worse than those of the breastfed infants. In our study, breastfeeding was done with mother's milk.

Here, a total number of 305 VLBWI (weight $\leq 1500 \mathrm{~g}$ ) were included. We analyzed different ratios of breast milk intake to the total intake of VLBW within four weeks after birth. The results showed that when breast milk intake accounted for more than $60 \%$ of the total intake, the incidence of LOS was significantly reduced. Currently, antibiotics are often used in clinical practice to prevent and treat LOS. Meanwhile, active nursing support treatment is also crucial for the prevention and treatment of LOS in premature infants $^{13}$. A large number of studies ${ }^{6,14,15}$ have found that breastfeeding can reduce the incidence of complications in preterm infants such as necrotizing enterocolitis and LOS. In another investigation, the incidence of VLBWI infectious diseases with exclusive breastfeeding was lower than that of the formulafed infants ${ }^{16}$. Furman ${ }^{17}$ compared several parameters between VLBWI and non-breastfeeding. Breastfeeding reached or exceed $50 \mathrm{~mL} / \mathrm{kg} / \mathrm{d}$, the incidence of LOS is reduced. In our study, the incidence of LOS was $2.6 \%$. The univariate analysis showed that the admission weight was related to the occurrence of LOS. Nevertheless, after adjustment for confounding variables related to gender, age, gestational age, and admission weight, the result was still valid, which is consistent with the results of the aforementioned study.

Studies have shown that, generally, after 34 weeks of gestation, the fetus obtains maternal immune protein from placental transfer, but the gestational age of VLBWI is generally less than 32 weeks. Therefore, VLBWI does not have sufficient immune protein at birth. Thus, low immunity after birth can facilitate the occurrence and development of various diseases ${ }^{18}$. The American Pediatric Association strongly recommends breastfeeding for preterm infants ${ }^{19}$. Breastfeeding is more conducive to the growth and development of preterm infants than formula feeding and reduces their infection rates. The breast milk of preterm infants contains more secreted immunoglobulin A $(\lg A)$, lysozyme, lactoferrin, and interferon than the breast milk of term infants ${ }^{20}$, which provides good conditions for development and protection to premature infants by enhancing their immunity and reducing the risk of infection ${ }^{21}$. A large number of studies ${ }^{16-18}$ have revealed that breastfeeding exerts a good protective effect in premature infants after reaching a certain proportion, which is consistent with the results of our study. Unlike previous studies, Our study found that the incidence of LOS in the low-proportion group was higher than 
that in the formula milk group, which may indicate that low-proportion breast-milk mixed feeding is more likely to occur when VLBWI is fed than full-formula.

In summary, within four weeks after birth of very-low-birth-weight infants, breastfeeding accounted for $60 \%$ of the total feeding amount, which reduced the incidence of VLBWI LOS. Formula feeding or mixed feeding should be reduced, and low breast milk mixed formula feeding should be avoided for exerting the beneficial effects of breast milk on premature infants. Therefore, in the early days after birth, highbreastfeeding regimen should be adopted in preterm infants as much as possible. Its protective effect reduces effectively the incidence of LOS in preterm infants, and at the same time promotes their smooth growth and development. The number of the positive cases in this study was too small, which might have led to an excessively wide confidence interval, leading to an unstable outcome. Therefore, a larger sample size needs to be employed in the follow-up study to confirm our findings.

\section{Conclusion}

The breastfeeding amount of very-low-birth-weight newborns accounting for more than $60 \%$ of the total feeding amount within four weeks after birth may reduce the risk of late-onset sepsis. Besides, VLBWI intake a small amount of breast milk mixed feeding or formula feeding may increase the incidence of LOS.

\section{Declarations}

\section{Acknowledgements:}

Thanks to Ms. Xiong who gave guidance and modify for the article, Dr. Chenfor giving guidance, and Ms. Lin and others for data collection.

\section{AUTHOR CONTRIBUTIONS STATEMENT:}

$\mathrm{HY}, \mathrm{W}$ is responsible for analyzing the data and writing the article, $\mathrm{LL}, \mathrm{C}$ is responsible for analyzing the data, $X Y, X$ and $X Y, C$ are responsible for revised the article, $B C, L$ and $C, C$ are responsible for data collection, $\mathrm{CZ}, \mathrm{Y}$ is responsible for data collection. And All authors reviewed the manuscript.

\section{Competing Interests:}

None of the authors have any competing financial interests.

\section{Data availability:}

The datasets analysed during the current study are not publicly available due to All data owned by Shenzhen Maternity and Child Healthcare Hospital, Southern Medical University, but are available from the corresponding author on reasonable request. 


\section{References}

1. Dessu S, Habte A, Melis T, Gebremedhin M. Survival Status and Predictors of Mortality among Newborns Admitted with Neonatal Sepsis at Public Hospitals in Ethiopia. International Journal of Pediatrics. 2020;2020:1-10

2. Stoll BJ, Hansen N, Fanaroff AA et al. Late-onset sepsis in very low birth weight neonates: the experience of the NICHD Neonatal Research Network. Pediatrics. 2002;110(2 Pt 1):285-91

3. Dewey KG, Heinig MJ, Nommsen-Rivers LA. Differences in morbidity between breast-fed and formula-fed infants. The Journal of pediatrics. 1995;126(5):696-702

4. Greenberg RG, Kandefer S, Do BT et al. Late-onset Sepsis in Extremely Premature Infants: 2000-2011. Pediatr Infect Dis J. 2017;36(8):774-779

5. Tsai M, Hsu J, Chu S et al. Incidence, Clinical Characteristics and Risk Factors for Adverse Outcome in Neonates With Late-onset Sepsis. Pediatr Infect Dis J. 2014;33(1):e7-e13

6. El Manouni El Hassani S, Berkhout DJC, Niemarkt HJ et al. Risk Factors for Late-Onset Sepsis in Preterm Infants: A Multicenter Case-Control Study. Neonatology. 2019;116(1):42-51

7. Gartner LM, Morton J, Lawrence RA et al. Breastfeeding and the use of human milk. Pediatrics. 2005;115(2):496-506

8. Lonnerdal B, Erdmann P, Thakkar SK, Sauser J, Destaillats F. Longitudinal evolution of true protein, amino acids and bioactive proteins in breast milk: a developmental perspective. J Nutr Biochem. 2017;41:1-11

9. Verduci E, Gianni ML, Di Benedetto A. Human Milk Feeding in Preterm Infants: What Has Been Done and What Is to Be Done. Nutrients. 2019;12(1)

10. Torres Roldan VD, Urtecho S M, Gupta J et al. Human milk oligosaccharides and their association with late-onset neonatal sepsis in Peruvian very-low-birth-weight infants. The American Journal of Clinical Nutrition. 2020;112(1):106-112

11. Boyd CA, Quigley MA, Brocklehurst P. Donor breast milk versus infant formula for preterm infants: systematic review and meta-analysis. Archives of Disease in Childhood - Fetal and Neonatal Edition. 2007;92(3):F169-F175

12. Verd S, Porta R, Botet F et al. Hospital Outcomes of Extremely Low Birth Weight Infants After Introduction of Donor Milk to Supplement Mother's Milk. Breastfeed Med. 2015;10(3):150-155

13. Colaizy TT, Carlson S, Saftlas AF, Morriss JFH. Growth in VLBW infants fed predominantly fortified maternal and donor human milk diets: a retrospective cohort study. Bmc Pediatr. 2012;12(1):124-124

14. Maayan-Metzger A, Avivi S, Schushan-Eisen I, Kuint J. Human Milk Versus Formula Feeding Among Preterm Infants: Short-Term Outcomes. Am J Perinat. 2012;29(02):121-126

15. Ginovart G, Gich I, Verd S. Human milk feeding protects very low-birth-weight infants from retinopathy of prematurity: a pre-post cohort analysis. J Matern Fetal Neonatal Med. 2016;29(23):3790-5 
16. Sisk PM, Lovelady CA, Dillard RG, Gruber KJ, O'Shea TM. Early human milk feeding is associated with a lower risk of necrotizing enterocolitis in very low birth weight infants. $J$ Perinatol. 2007;27(7):428-33

17. Furman L, Taylor G, Minich N, Hack M. The effect of maternal milk on neonatal morbidity of very lowbirth-weight infants. Archives of pediatrics \& adolescent medicine. 2003;157(1):66

18. O'Connor DL, Jacobs J, Hall R et al. Growth and Development of Premature Infants Fed Predominantly Human Milk, Predominantly Premature Infant Formula, or a Combination of Human Milk and Premature Formula. J Pediatr Gastr Nutr. 2003;37(4):437-446

19. Cortez J, Makker K, Kraemer DF et al. Maternal milk feedings reduce sepsis, necrotizing enterocolitis and improve outcomes of premature infants. J Perinatol. 2018;38(1):71-74

20. Murphy JF, Neale ML, Matthews N. Antimicrobial properties of preterm breast milk cells. Arch Dis Child. 1983;58(3):198-200

21. Kramer MS, Chalmers $B$, Hodnett ED et al. Promotion of Breastfeeding Intervention Trial (PROBIT): a randomized trial in the Republic of Belarus. JAMA. 2001;285(4):413-20 